Case Report

\title{
Recurrent Occipital Dermatofibrosarcoma Protuberans: Multidisciplinary Management of a Rare Case
}

\author{
Mubashir Malik, Zubair Ahmed Khan, Rabia Saleem, Shahzad Safdar, Touqeer Ahmed \\ Department of Neurosurgery, Punjab Institute of Neurosciences, Lahore - Pakistan
}

\begin{abstract}
Dermatofibrosarcoma protuberans (DFSP) is a skin tumor arising from the dermis, slow-growing in nature and locally invasive. The most common localities of DFSP are on the extremities and rarely on the head and neck. We are presenting a case of 24 years old male with a huge recurrent DFSP lesion in the occipital region. We did wide local excision with tumor-free skin margins of $2.5 \mathrm{~cm}$ followed by excision of the involved occipital bone and wound coverage with external carotid artery flap.
\end{abstract}

Keywords: Dermatofibrosarcoma (DFSP), occipital bone, multidisciplinary, wide local excision.

\section{INTRODUCTION}

Dermatofibrosarcoma also known as dermatofibrosarcoma protuberans (DFSP) is a tumor of skin arising from the dermis, slowgrowing and locally invasive. ${ }^{1}$ Most common locations of DFSP are extremities and trunk(80\%) but rarely only approx. $5 \%$ on head and neck region. $^{2}$ DFSP can present as a slow-growing

Corresponding Author: Mubashir Malik

Department of Neurosurgery

Punjab Institute of Neurosciences, Lahore - Pakistan

Email: drmubashirmalik151@gmail.com

Date of Submission: 24-07-2021

Date of Revision: 05-09-2021

Date of Acceptance: 15-09-2021

Date of Online Publishing: 30-09-2021

Date of Print: 30-09-2021

DOI: $10.36552 /$ pjns.v25i3.564 swelling which is initially pale red or brown nodule on the skin and can cause disfigurement, local pain, and skin excoriation when size increases. ${ }^{3}$ DFSP of scalp region can also present as intracranial lesions but is very rare. ${ }^{4}$

Management of DFSP includes a multidisciplinary approach including histological diagnosis and wide local excision of the tumor with the removal of involved bone and muscle as defined of at least $2.5 \mathrm{~cm}$ tumor-free margins. ${ }^{2,3}$

The main aim was to achieve three goals i.e. i) Tumor free margins of at least $2.5 \mathrm{~cm}$, ii) Prevention of function and cosmesis, and iii) Patient convenience and cost-effectiveness of treatment. ${ }^{5}$ After wide local excision of DFSP, local skin grafts or flaps necessarily require for better cosmetic outcome. ${ }^{6}$

\section{Case}

A 24 years male presented with recurrent swelling 
in the occipital region of the head for the last 3 years which was slowly increasing in size, causing disfigurement and left-sided head tilt due to increased size and weightof the lesion. Previously incomplete excision of this swellingwas done 3 times in the last three years with histological diagnosis of DFSP. He has no other comorbidities and his family history was not significant.

He later presented in our neurosurgery department with a large disfiguring masson the scalp in the occipital region which was $20 \mathrm{~cm} \times$ $30 \mathrm{~cm}$ in size with skin crusts and infestation of Maggots. No lymphnodes were palpable in the head and neck region and the rest of the systemic examination was normal.

\section{Investigations}

On CT-scan Brain with intravenous contrast axial and sagittal sections showed a large mass arising from the skin in the parietal occipital region of scalp involving the outer table of occipital bone as shown in Figure 2.

\section{Treatment}

DFSP is a challenging skin tumor with a high recurrence rate and should be managed by a multidisciplinary approach.

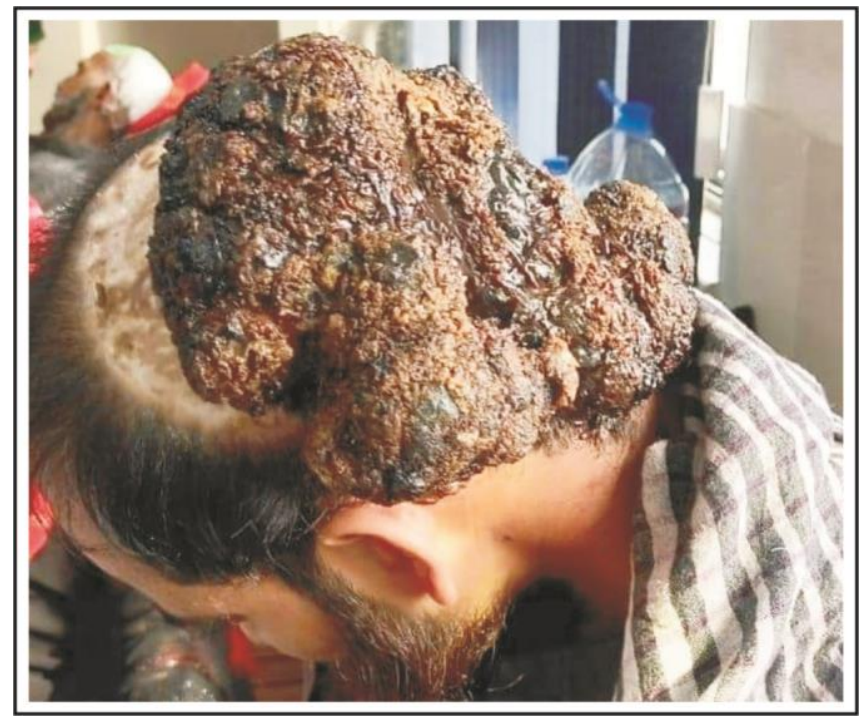

Figure 1: The external appearance of the lesion in lateral and posterior view (photograph used with patient's permission).

The multidisciplinary treatment plan was devised for the patient in two stages.

Stage 1: Under general anesthesia, wide local excision with excision of the involved occipital bone was done along with $>2.5 \mathrm{~cm}$ of tumor-free skin margins as described in literature craniectomy defect remained intact for cranioplasty till the external carotid flap success.

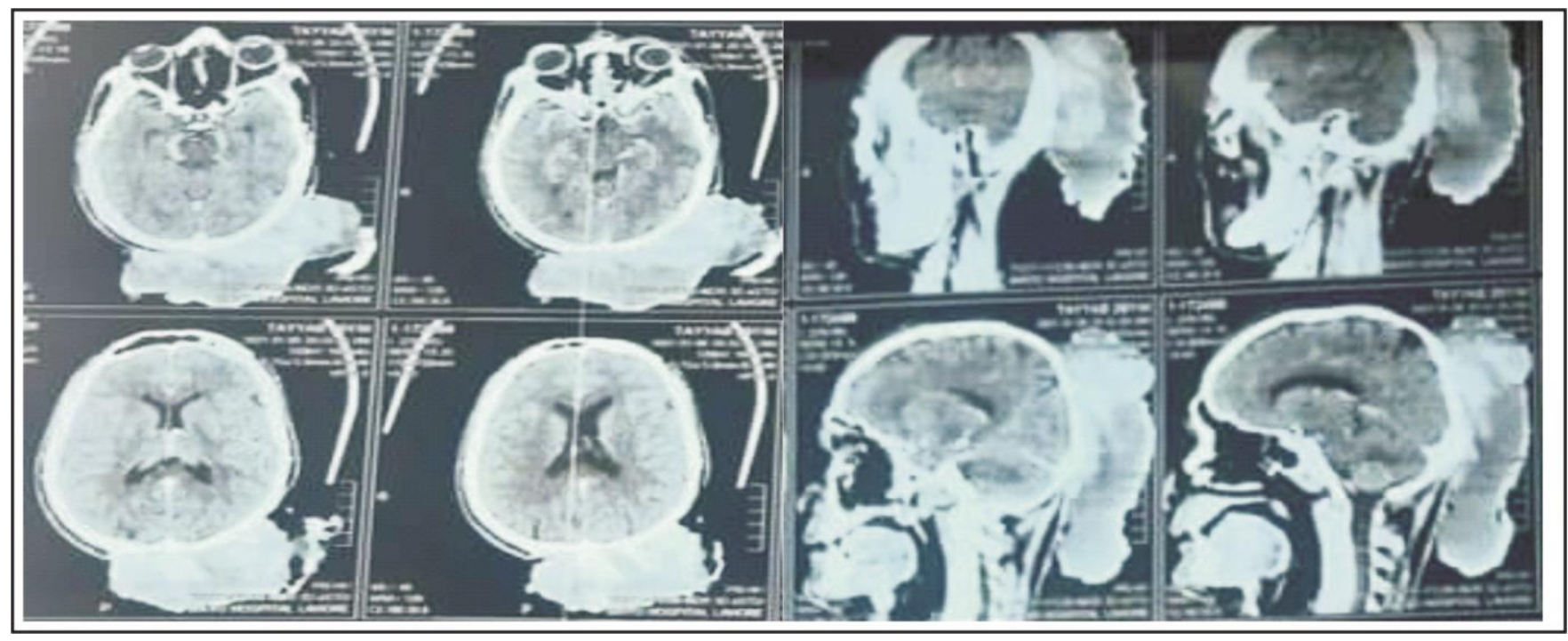

Figure 2: CT-scan Brain Plain Axial and Sagittal Sections. 
Stage 2: External Carotid artery flap was done by the plastic surgery department for coverage of the exposed area in the occipital region for better cosmetic outcome after the arrival of histopathology report confirming tumor-free margins of skin as shown in Figure 3.

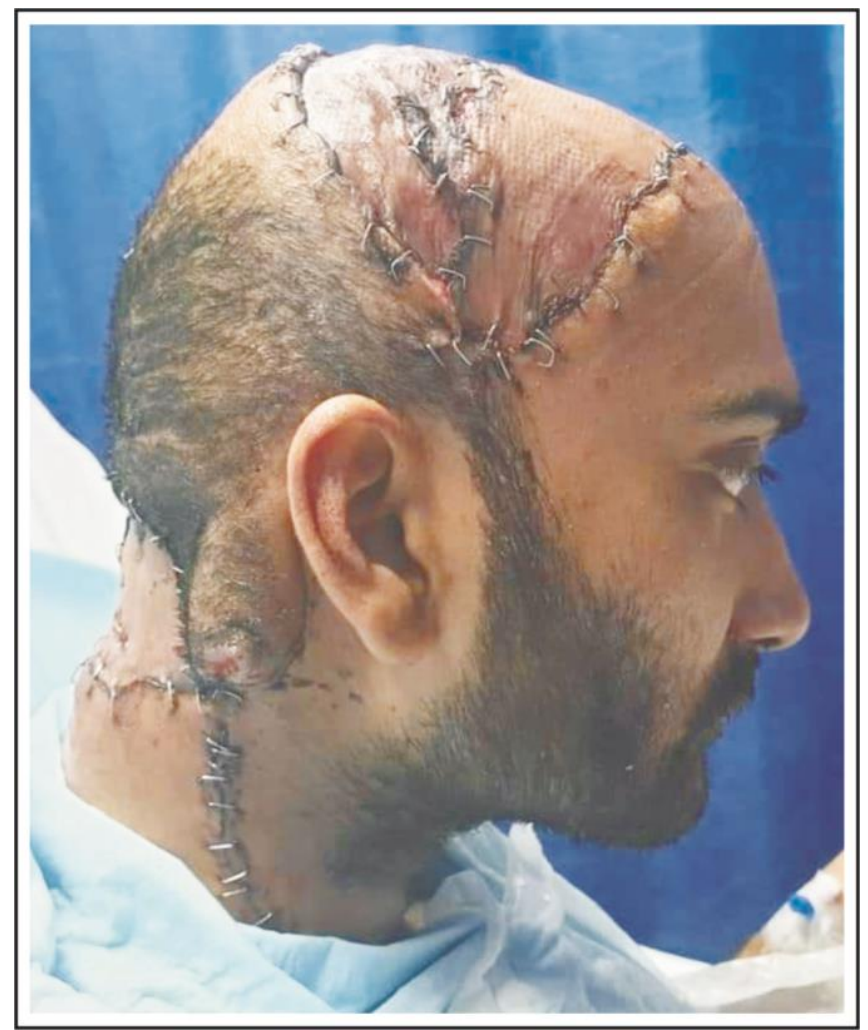

Figure 3: Post-operative after wide local excision and external carotid artery flap (photograph used with patient's permission).

\section{DISCUSSION}

DFSP is a cutaneous tumor arising from the dermis and rarely present in the head and neck region. ${ }^{2}$ It is a locally invading tumor with rare distant metastasis. DFSP is an indolent tumor with a high recurrence rate. ${ }^{7}$

DFSP presents in the head and neck region can cause disfigurement, pain, and other local skin problems which cause morbidity in patients.

DFSP diagnosis is made after the clinical examination of the lesion and on initial histopathology. Large size lesions especially presenting in head and neck regions warrants further investigation like CT-scan head and neck or MRI head and neck with intravenous contrast to see the extent of local invasion, vascularity, and metastasis in lymph nodes.

Treatment strategy should be a multidisciplinary approach involving the radiology, oncology, pathology, plastic surgery, and neuro-surgical departments.

The main target for the cure of DFSP is to achieve tumor-free skin margins of $>2.5 \mathrm{~cm}$ in almost $95 \%$ of cases after wide local excision and wound coverage with skin grafts or flaps. ${ }^{6,8}$

We encountered the above-mentioned recurrent case of DFSP in the occipital region invading locally and involving the occipital bone and transverse sinus of the Dura mater of the brain. Wide local excision was done with tumorfree skin margins of approximately $2.5 \mathrm{~cm}$ and removal of the involved occipital bone. Later the wound defect coverage was done by the plastic surgery department with a carotid artery flap for a better cosmetic outcome. Histopathology confirmed the DFSPof skin with tumor-free margins.

\section{CONCLUSION}

DFSP is a challenging skin tumor that is indolent, highly recurrent, and rare in the head and neck region. Wide local excision with tumor-free margins and proper wound coverage should have opted asan optimal treatment regimen. This warrants a multidisciplinary approach with regular follow-up visits for the cure of DFSP.

\section{REFERENCES}

1. Kho JP, $\mathrm{Ng} \mathrm{BH}$, John R. Recurrent occipital dermatofibrosarcoma protuberans tackled with wide local excision: A case report and current management. The Medical journal of Malaysia, 2019; 74 (1): 82-4. 
2. Sangrador $M$, Olvera JG, Ortiz VM. Dermatofibrosarcoma of the scalp. Surgical Neurology International, 2019: 10.

3. Lyu A, Wang Q. Dermatofibrosarcoma protuberans: A clinical analysis. Oncology Letters, 2018; 16 (2): 1855-62.

4. Das L, Grover SB, Chand K, Dawson L. Intracranial extension of a dermatofibrosarcoma protuberans of the scalp: a case report with brief review of literature. Surgical Neurology, 2000; 54 (6): 452-4.

5. Mullen JT. Dermatofibrosarcoma protuberans: wide local excision versus Mohs micrographic surgery. Surgical Oncology Clinics, 2016; 25 (4): 827-39.

6. DuBay D, Cimmino V, Lowe L, Johnson TM, Sondak
VK. Low recurrence rate after surgery for dermatofibrosarcoma protuberans: a multidisciplinary approach from a single institution. Cancer, 2004; 100 (5): 1008-16.

7. Farma JM, Ammori JB, Zager JS, Marzban SS, Bui MM, Bichakjian CK, Johnson TM, Lowe L, Sabel MS, Wong SL, Letson GD. Dermatofibrosarcoma protuberans: how wide should we resect? Annals of Surgical Oncology, 2010; 17 (8): 2112-8.

8. Wiesmueller F, Agaimy A, Perrakis A, Arkudas A, Horch RE, Grützmann $R$, Vassos $N$. Dermatofibrosarcoma protuberans: surgical management of a challenging mesenchymal tumor. World Journal of Surgical Oncology, 2019; 17 (1): 1-9.

\section{Additional Information}

Disclosures: Authors report no conflict of interest.

Ethical Review Board Approval: The study was conformed to the ethical review board requirements.

Human Subjects: Consent was obtained by the patient in this study. Photographs are included with his consent. Conflicts of Interest:

In compliance with the ICMJE uniform disclosure form, all authors declare the following:

Financial Relationships: All authors have declared that they have no financial relationships at present or within the previous three years with any organizations that might have an interest in the submitted work.

Other Relationships: All authors have declared that there are no other relationships or activities that could appear to have influenced the submitted work.

\section{AUTHORS CONTRIBUTIONS}

\begin{tabular}{|l|l|l|}
\hline Sr.\# & Author's Full Name & Intellectual Contribution to Paper in Terms of: \\
\hline 1. & Mubashir Malik & Study Design and Methodology. \\
\hline 2. & Zubair Ahmed Khan & Paper Writing and Data Calculations. \\
\hline 3. & Rabia Saleem & Data Collection and Calculations. \\
\hline 4. & Shahzad Safdar & Analysis of Data and Interpretation of Results etc. \\
\hline 5. & Touqeer Ahmed & Literature Review and Referencing. \\
\hline 6. & Asad-ur-Rehman & Analysis of Data and Quality Insurer. \\
\hline
\end{tabular}

